\title{
FE Simulation of Welding Distortion and Residual Stresses in Butt Joint Using Inherent Strain
}

\author{
Asifa Khurram and Khurram Shehzad
}

\begin{abstract}
This paper presents an efficient FE technique using equivalent load to precisely predict welding deformations and residual stresses in butt joints. Equivalent load method is based on inherent strains which are a function of the highest temperature and degree of restrain. Nonlinear FE transient thermal analysis is performed using surface heat source model with Gaussian distribution to compute highest temperature in mild steel plates. Equivalent loads are calculated by integration of inherent strain components in MATLAB. An elastic FE analysis of weldment using these equivalent loads is performed to simulate deformation and residual stresses. Predicted distortions show a good agreement with the experimental measurements, which prove the reliability of the proposed technique.
\end{abstract}

Index Terms-Butt weld, inherent strain, FEM, residual stress.

\section{INTRODUCTION}

Welding is the non-detachable joining or coating of components or base material under the focused application of heat or pressure, with or without the use of filler metal. Due to highly localized transient heat input, significant deformations and residual stresses occur during and after welding. In manufacturing, welding deformations jeopardize the shape and dimensional tolerance required, whereas, residual stresses reduce fatigue strength, corrosion resistance and stability limit.

To improve fabrication quality and reduce repair work, research on welding distortions and residual stresses has been a continuous interest among researchers. The destructive and nondestructive techniques to evaluate residual stresses are X-ray diffraction method [1], neutron diffraction method [2]-[3], layer-removal method, sectioning method, ultrasonic and magnetic methods, and hole drilling method [4]-[5]. However, these methods are extremely complicated with limited application owing to cost or accuracy. Finite element simulation proved to be a proficient tool to predict welding distortion and residual stresses in welded structures with accuracy [6]-[7].

In this study, equivalent load method based on inherent strain theory is used to predict welding deformation and residual stresses in butt welded plates. Transverse shrinkage, longitudinal shrinkage and out of plane deformations of the specimen are computed by FE simulation and validated with

Manuscript received August 2, 2012; revised September 21, 2012

A. Khurram is with the College of Materials Science and Chemical Engineering, Harbin Engineering University, China (e-mail: Asifa_khuram@hotmail.com).

K. Shehzad is with the college of Shipbuilding Engineering, Harbin Engineering University, Harbin, China (e-mail: khurram_1977@hotmail.com). experimental measurements. In addition, von-mises residual stress distribution is also predicted. A good agreement of simulated and experimental results shows the efficacy of this method.

\section{THEORATICAL BACKGROUND}

\section{A. Inherent Strain}

Weld joint is generally divided into three parts; weld region, material softening region, and base metal region [8]. Weld region, also called inherent strain region, experiences rapid temperature rise above critical temperature which causes plastic strains. These strains remain to some extent after cooling, known as inherent strains. However, in material softening region material properties are softened but plastic strains do not appear. The base metal region, also called elastic region, has the material properties of room temperature and remains elastic.

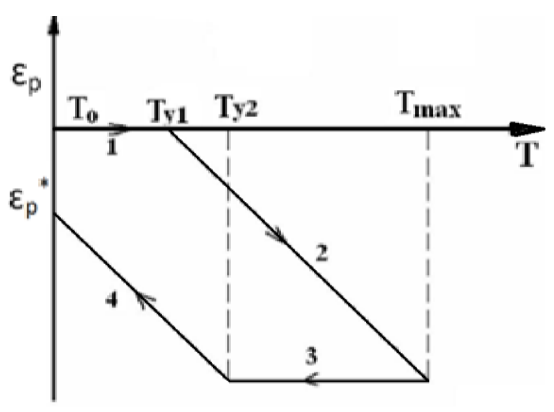

Fig. 1. Thermal history of inherent strain.

According to temperature variations of the weld region, the thermal history of the inherent strain can be divided into four steps as shown in Fig. 1. At the end of the thermal cycle, compressive plastic strains remain as an amount of $\varepsilon^{*}$, which is determined as a function of highest temperature and degree of restraint $\beta$. Inherent strains exhibit different patterns with respect to peak temperatures within the weld area and are calculated refer to (1) [9]-[10].

$$
\begin{array}{cc}
\varepsilon^{*}=0 & T_{\max }<T_{1} \\
\varepsilon^{*}=\frac{\varepsilon y}{\beta}-\alpha T_{\max } & T_{1}<T_{\max }<2 T_{1} \\
\varepsilon^{*}=\frac{\varepsilon y}{\beta} & 2 T_{1}<T_{\max }
\end{array}
$$


where, $\varepsilon^{*}$ is the strain, $\varepsilon_{y}$ is yield strain, $T_{\max }$ is the maximum temperature and $T_{1}$ is yield temperature or critical temperature during heating and is determined by using (2).

$$
T_{1}=\frac{\delta y}{\beta E \alpha}
$$

In this connection, $\sigma_{y}$ is the yield stress $E$ is Young's modulus and $\alpha$ is thermal expansion coefficient.

\section{B. Degree of Restaint}

The degree of restraint represents the level of resistance of the base metal against the thermal deformation of the welding region. Degree of restraint is determined by the stiffness of bar and spring model shown in Fig. 2 refer to (3) [10]. A bar represents Inherent strain region, whereas remaining base metal region represents a spring.

$$
\beta=\frac{k s}{(k+k s)}
$$

where, $k_{s}$ and $k$ are the stiffness of spring base metal region and inherent strain region respectively.

\section{Equivalent Load Calculation}

Equivalent load as shrinkage force is computed using (4) by integrating inherent strains [11].

$$
\begin{aligned}
& f_{1}=\frac{A E}{l} \sum_{j=1}^{N t} \varepsilon_{j}^{*} l_{j} \\
& f=\sum_{i=1}^{N i} f_{i}
\end{aligned}
$$

where, $l_{j}$ is the length of unit $j, \mathrm{~A}$ is area and $f$ is equivalent force.

\section{EXPERIMENTAL PROCEDURE}

To authenticate the simulation technique, experiments were conducted on two specimen mild steel plates of size $400 \mathrm{~mm}$ $(L) \times 400 \mathrm{~mm}(W)$ with thickness $10 \mathrm{~mm}$ and $16 \mathrm{~mm}$ respectively. Geometric model of the plate is shown in Fig. 3. A bead on plate was applied by electric arc welding process along $\mathrm{X}$-axis using parameters summarized in Table I.

TABLE I: WELDING PARAMETERS.

\begin{tabular}{|l|l|l|l|l|}
\hline Current & Voltage & Speed & Efficiency & Room Temp \\
\hline $300(\mathrm{~A})$ & $30(\mathrm{~V})$ & $5(\mathrm{~mm} / \mathrm{s})$ & $70 \%$ & $10{ }^{\circ} \mathrm{C}$ \\
\hline
\end{tabular}

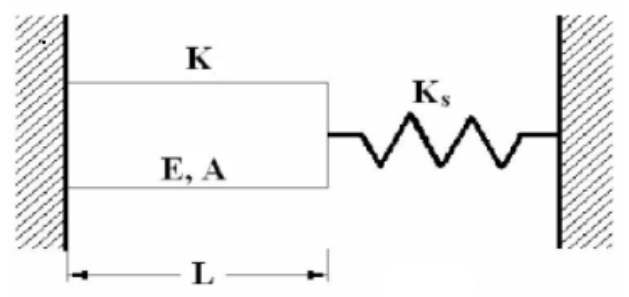

Fig. 2. Simplified thermal elasto-plastic analysis model.

\section{Simulation OF Welding Deformation}

Welding deformations of butt welded plates have been predicted using equivalent load method based on inherent strain and FE analysis. Various steps involved in simulation process are transient thermal $\mathrm{FE}$ analysis, equivalent load calculation using inherent strain data and an elastic FE structure analysis of full 3D model.

\section{A. Thermal Analysis}

Temperature distribution in the weld region is assessed by performing a 3D nonlinear transient thermal analysis, using commercially available FEM code ANSYS. Keeping in view the symmetry, half of the plate is modeled. A fine mapped mesh is adopted in the welding area in order to apply heat flux accurately, whereas remaining areas have relatively coarser mesh. Temperature dependent thermal properties of mild steel are considered for the purpose of analysis as shown in Fig. 4 [12]. Heat of the welding arc is modeled as surface heat source following Gaussian distribution [13]. An APDL subroutine is used to define heat flux density q transferred to each point on the surface around the welding line at each time step using (5).

$$
q(x, y)=\frac{3 Q}{\pi r^{2}} e-3 \frac{x^{2}}{r^{2}}-3 \frac{z^{2}}{r^{2}}
$$

where, $\mathrm{r}$ is the arc radius and $Q=\eta V I$ is the heat input rate, determined by welding current $I$, voltage $V$ and efficiency $\eta$, respectively. Convection boundary condition is applied on the surfaces to accommodate heat flux loses according to (6) [14].

$$
q_{c}=h\left(T-T_{0}\right)
$$

where, $q_{c}$ is heat loss due to convection, $h=15 \mathrm{Wm}-2$ is convection coefficient and $\mathrm{T}_{0}$ is room temperature.

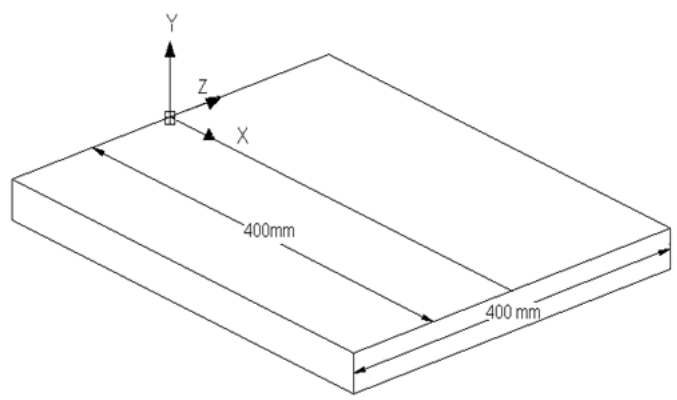

Fig. 3. Specimen plate geometry.

\section{B. Structural Analysis}

Inherent strains are computed using temperature distribution results of thermal analysis and subsequently integrated in MATLAB software to obtain equivalent transverse and longitudinal forces on weld area. Welding deformations and residual stresses are computed by elastic structural analysis of full FE model of plate using the same 
meshing approach of thermal analysis. Modulus of elasticity value of $2.1 \mathrm{e} 11 \mathrm{~N} / \mathrm{m}^{2}$ for mild steel is used in this analysis.

\section{RESULTS AND DISCUSSION}

\section{A. Welding Deformations}

The deformation normal to the weld line is called transverse deformation and parallel to the weld line is called longitudinal deformation. These deformations arise due to the shrinkage forces generated during the thermal cycle. Out of plane deformation or deformation normal to the plane of weld occurs due to a non-uniform thermal contraction through plate thickness. Fig. 5 demonstrates predicted deformation modes of $10 \mathrm{~mm}$ welded plate. It is obvious that out of plane dominates other two deformation modes.

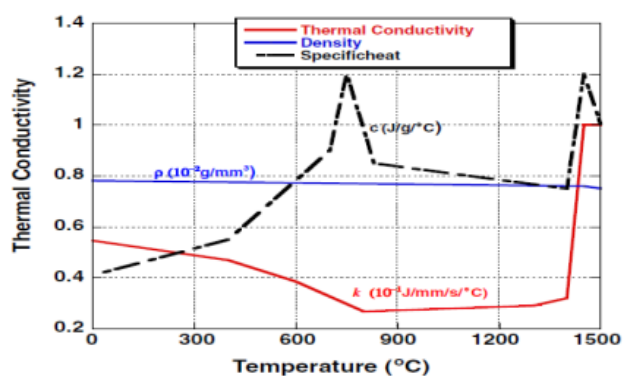

Fig. 4. Temperature dependent material properties.

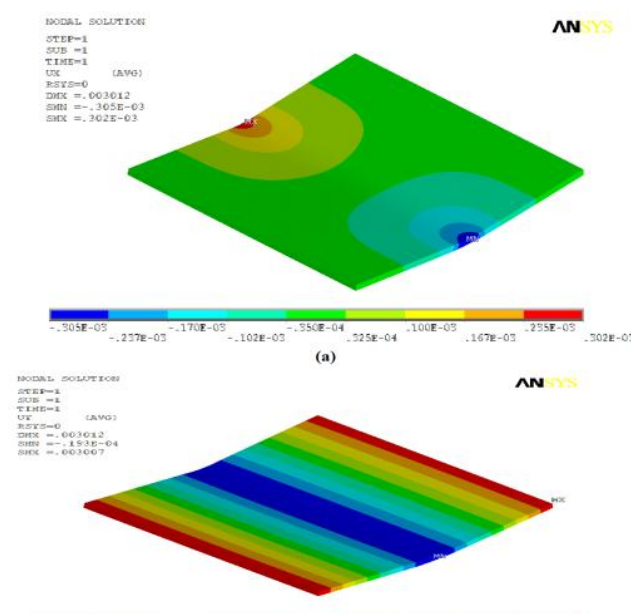

(b)

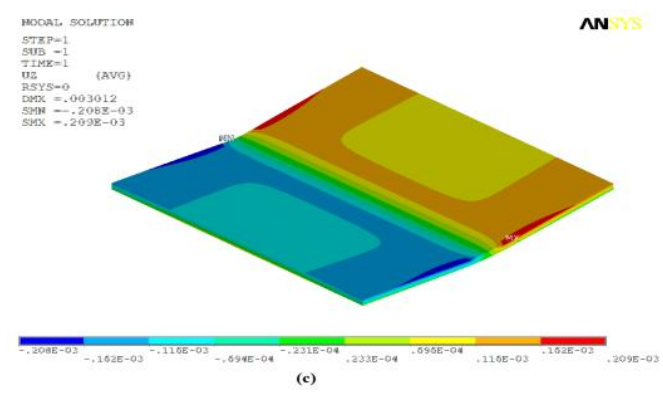

Fig. 5. Predicted deformation modes (a) Longitudinal (b) Out of plane (c) Transverse.

Fig. 6 shows the predicted deformation from elastic FE analysis and comparison with experimental values of both plates at mid-section. From Fig. 6a and Fig. 6b, it is evident that small plate thickness results in greater deformation value. Comparison of experiment and predicted values of maximum longitudinal deformation at the start and end points of welding line is presented in Table II. Results demonstrate a close agreement of predicted and experimental deformation values.

\section{B. Residual Stresses in Weld}

Fig. 7 shows vonmises stress distribution across the plate thickness in transverse direction at mid span. There is a gradual decrease in residual stresses from top to bottom surface. Fig. 8 shows total deformation and vonmises residual stresses in transverse direction at mid thickness for 16mm specimen plate. Residual stresses exhibit a sharp decreasing trend in the areas near the weld region, whereas, deformations increases gradually in transverse direction.

Fig. 9 reveals the effect of plate thickness on vonmises residual stress distribution. Reduced residual stresses are observed in areas after the fusion zone with an increase in plate thickness.
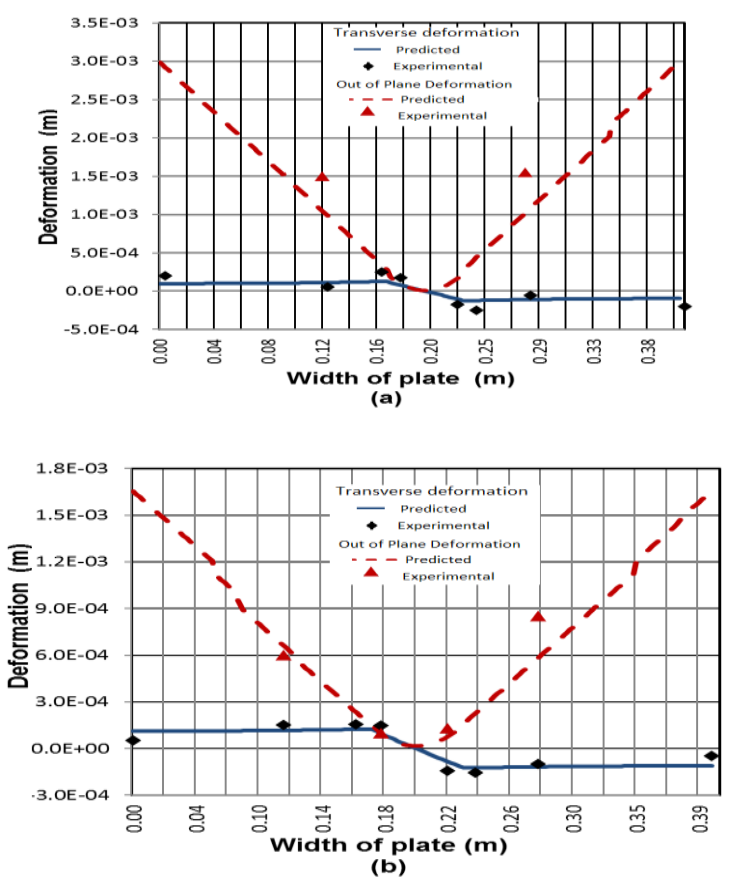

Fig. 6. Transverse and out of plane deformation at mid-section (a) $10 \mathrm{~mm}$ plate thickness (b) $16 \mathrm{~mm}$ plate thickness.

TABLE II: LONGITUDINAL DEFORMATION AT WELD LINE.

\begin{tabular}{|c|c|c|c|}
\hline Plate Thickness & Predicted & Experimental & \% Difference \\
\hline $16 \mathrm{~mm}$ & $0.16 \mathrm{~mm}$ & $0.15 \mathrm{~mm}$ & $6 \%$ \\
\hline $10 \mathrm{~mm}$ & $0.305 \mathrm{~mm}$ & $0.35 \mathrm{~mm}$ & $12.8 \%$ \\
\hline
\end{tabular}

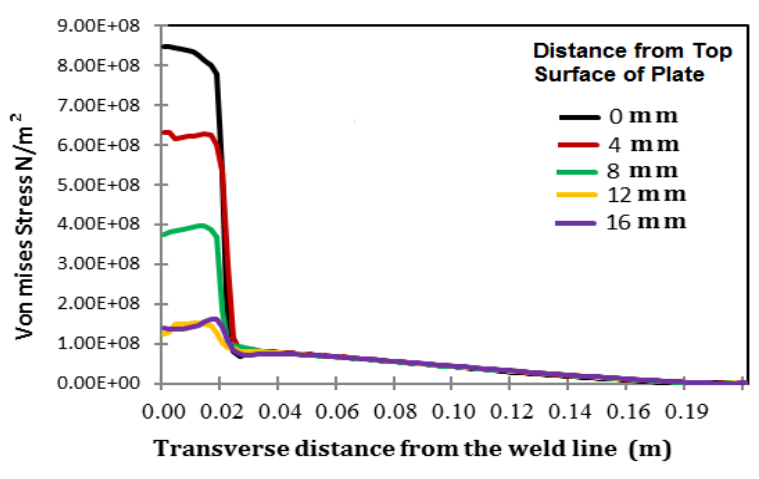

Fig. 7. Vonmises stress distribution across plate thickness at mid span. 


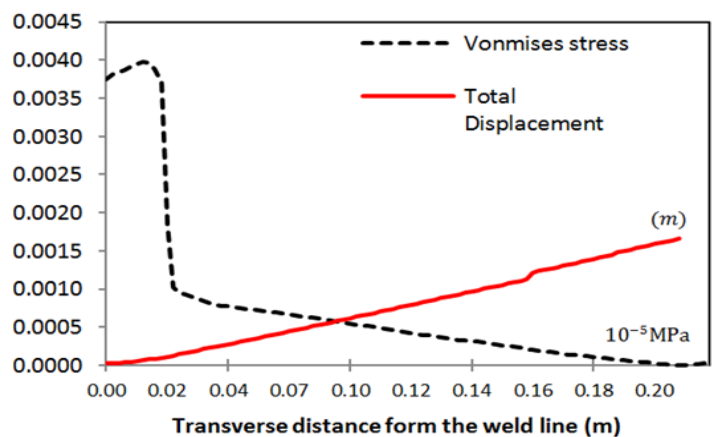

Fig. 8. Vonmises residual stress at mid thickness and total deformation.

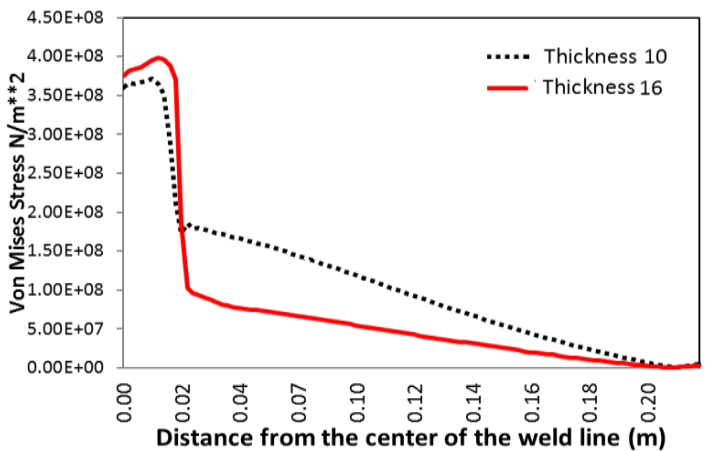

Fig. 9. Vonmises residul stress distribution in transverse direction for different plate thickness.

\section{CONCLUSION}

In this paper, FE Simulation technique using equivalent load method based on inherent strain to predict deformation and residual stresses for bead on plate welding is presented. This research provides basic theory and instruction to simulate welding residual stresses and deformations. A nonlinear transient thermal analysis is performed using a moving heat source based on Gaussian distribution. The temperature distribution as a consequence of thermal load is employed to calculate equivalent shrinkage forces. 3D finite element elastic structural analysis is conducted to estimate the deformations and residual stresses.

Bead on plate experiments are also performed to validate the simulation method. Conclusions summarized are;

1) Simulated results are in a good agreement with experimental values, which shows the reliability of equivalent load method.

2) Analysis results reveal that the value of out of plane deformation is much higher as compared to transverse and longitudinal deformations.

3) Vonmises residual stress decreases rapidly in transverse direction in areas near the weld region. In contrast, welding deformation shows a smooth continuous increasing behavior.

4) The residual stress distribution is not uniform through the thickness of plate with maximum value at the top surface of plate and decrease gradually to minimum at the bottom.

5) Every mode of deformation has greater value in case of lesser thickness.

6) An increase in plate thickness results in reduction of residual stresses in areas adjacent to fusion zone.

\section{REFERENCES}

[1] P. J. Withers and H. K. D. H. Bhadeshia, "Residual stress Part 1 measurement techniques," Materials Science and Technology, vol. 17, pp. 355-365, 2001.

[2] M. J. Park, H. N. Yang, D. Y. Jang, J. S. Kim, and T. E. Jin, "Residual stress measurement on welded specimen by neutron diffraction," Journal of Materials Processing Technology, vol. 155-156, pp. 1171-1177, 2004.

[3] R. A. Owen, R. V. Preston, P. J. Withers, H. R. Shercliff, and P. J. Webster, "Neutron and synchrotron measurements of residual strain in TIG welded aluminum alloy 2024," Materials Science and Engineering, vol. A346, pp. 159-167, 2003.

[4] G. S. Schajer, "Measurement of non-uniform residual stresses using the hole-drilling method Part. I-II," Journal of Engineering Materials and Technology, vol. 110, pp. 338-343, 1988.

[5] G. Roy, M. Braid, and G. Shen, "Application of ADINA and hole drilling method to residual stress determination in weldments," Computers and Structures, vol. 81, pp. 929-935, 2003.

[6] S. Sarkani, V. Tritchkov, and G. Michaelov, "An efficient approach for computing residual stresses in welded joints," Finite Elements in Analysis and Design, vol. 35, pp. 247-268, 2000.

[7] J. Mackerle, "Finite element analysis and simulation of welding - an addendum: a bibliography (1996-2001)," Modelling Simul. Mater. Sci. Eng. , vol.10, pp. 295-318, 2002.

[8] S. Seo and C. D. Jang, "A study on the prediction of deformations of welded ship structures," Journal of Ship Production, vol. 15, pp. 73-81, 1999.

[9] H. Murakawa, Y. Luo, and Y. Ueda, "Prediction of welding deformation and residual stress by elastic FEM based on inherent strain," Trans. JWRI, vol. 26, no. 2, pp. 49-57, 1997 [Soc. Nav. Architects of Japan, pp. 739-751, 1997].

[10] C. D. Jang, C. H. Lee, and D. E. Ko, "Prediction of welding deformations of stiffened panels," Proc. Instn. Mech. Engrs., vol. 216, pp.133-143, 2002

[11] L. Hong and H. Ren, "Simulation of Welding Deformations of Ship Structures," Key Engineering Materials Vols. vol. 324-325, pp. 651-654, 2006.

[12] D. Deng and H. Murakawa, "Prediction of welding distortion and residual stress in a thin plate butt welded joint," Computational Materials Science, vol. 43, pp. 353-365, 2008.

[13] D. Deng, W. Liang, and H. Murakawa, "Determination of welding deformation in fillet-welded joint by means of numerical simulation and comparison with experimental measurements," Journal of Materials Processing Technology, vol.183, pp. 219-225, 2007.

[14] D. Gery, H. Longb, P. Maropoulos, "Effects of welding speed, energy input and heat source distribution on temperature variations in butt joint welding," Journal of Materials Processing Technology, vol. 167, pp. 393-401, 2005.

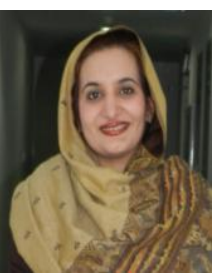

Asifa Khurram is a Phd candidate at college of Harbin Engineering University. He received MS in Mechanical Design Engineering from Harbin Engineering University in March 2007 and BS degree in Mechniacal Engineering from University of engineering and technology Taxila, Pakistan in December 2000. He is engaged in research work on welding simulation and structural strength assessment.

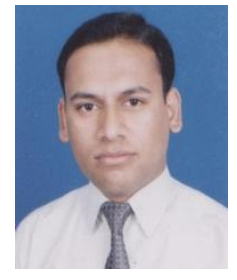

Khurram Shehzad is a Phd candidate for design and construction of naval architecture and ocean structure at Harbin Engineering University. He received $\mathrm{Ms}$ in Marine Engineering from Harbin Engineering University in March 2007 and BS degree in mechniacal engineering from University of Engineering and Technology Taxila, Pakistan in December 2000. He is engaged in research work on fatigue assessment of ship structures. 